\title{
Avaliação in vitro de genótipos de citros a Phytophthora parasitica
}

\author{
Amauri Siviero' ${ }^{1}$, Francineide A. Santos ${ }^{2}$, Mariângela Cristofani ${ }^{2}$, Edson L. Furtado ${ }^{1}$ \& Marcos A. Machado ${ }^{2}$ \\ 'Departamento de Produção Vegetal, Faculdade de Ciências Agronômicas, Cx. Postal 237, CEP 18603-970, \\ Botucatu, SP, e-mail: asiviero@ hotmail.com; ${ }^{2}$ Centro Avançado de Pesquisa Tecnológica de Citros 'Sylvio Moreira', \\ Instituto Agronômico de Campinas, Cx. Postal 04, CEP 13490-970, Cordeirópolis, SP
}

(Aceito para publicação em 02/07/2002)

Autor para correspondência: Amauri Siviero

SIVIERO, A., SANTOS, F.A., CRISTOFANI, M., FURTADO, E.L. \& MACHADO, M.A. Avaliação in vitro de genótipos de citros a Phytophthora parasitica. Fitopatologia Brasileira 29:300-302. 2004.

\section{RESUMO}

Este trabalho teve como objetivo avaliar in vitro a reação de porta-enxertos de citros (Citrus spp.) a Phytophthora parasitica. As plântulas foram cultivadas em meio MS por 40 dias sendo, submetidas a fotoperíodo de $18 \mathrm{~h}$, à temperatura de $25^{\circ} \mathrm{C}$. A inoculação foi realizada através da inserção de agulha infestada com micélio de $P$. parasitica. A avaliação foi realizada aos 15 dias após a inoculação, medindo-se o comprimento das lesões em centímetros. O delineamento experimental foi inteiramente casualizado, com 15 repetições. Os resultados estão de acordo com as reações de campo dos genótipos e podem ser de grande utilidade em trabalhos envolvendo resistência varietal e seleção precoce de plantas.

Palavras-chave adicionais: citros, resistência a doenças, seleção precoce.

\begin{abstract}
Evaluation in vitro of citrus rootstocks to Phytophthora parasitica

The objective of this work was to evaluate the effect on citrus (Citrus spp.) rootstocks to Phytophthora parasitica by in vitro inoculation. Seedlings were cultivated in MS media for 40 days, under $18 \mathrm{~h}$ of light

of photoperiod and at $25^{\circ} \mathrm{C}$. Inoculation was performed by injecting an infested needle into seedling collars. Evaluation was made by the length of lesions in centimeters. The experimental design was random with 15 replicates of each genotype. Results indicate good correlation between in vitro and orchard reactions genotypes to $P$. parasitica.
\end{abstract}

Entre as principais doenças provocadas por Phytophthora parasitica Dastur [sin. Phytophthora nicotianae Breda de Hann var. parasitica (Dastur) Waterhouse] na cultura de citros (Citrus spp.) no Brasil, se destaca a gomose de Phytophthora. A identificação e a seleção de genótipos resistentes a gomose é uma etapa importante no programa de melhoramento de citros. A literatura é escassa em trabalhos envolvendo a seleção in vitro de genótipos no patossistema citros-Phytophthora. Vardi et al. (1986) usaram filtrados de $P$. citrophthora em calos de quatro genótipos de citros, visando a seleção in vitro de genótipos para a resistência à doença, no entanto, não obtiveram sucesso nos experimentos. Crino $e t$ al. (1996) testaram in vitro toxinas de patógenos, enzimas purificadas e filtrados de patógenos de plantas em diversos patossistemas. No caso de P. nicotianae - tomate (Lycopersicon esculentum Mill.), o uso de filtrado do patógeno foi eficiente na seleção de genótipos resistentes/suscetíveis. No patossistema Phoma tracheiphila (Petri) Kanchaveli \& Gikashvili - limão [Citrus limon (L.) Burn. f.], a toxina do patógeno foi capaz de discriminar genótipos resistentes de suscetíveis.

A reação da resistência dos genótipos in vitro deve apresentar o mesmo comportamento em relação ao patógeno em campo. Trabalhos em condições axênicas demonstram que genótipos de porta-enxertos para citros podem ser avaliados, in vitro, inoculando-se plântulas de híbridos de Poncirus trifoliata (L.) Raf. (Bowman, 1996). A idade da planta e a luz são fatores que afetam a expressão da resistência dos genótipos em experimentos conduzidos in vitro no patossistema citros - P. parasitica (Bowman \& Graham, 1996). Siviero et al. (2001) avaliaram a resistência de quatro portaenxertos de citros à $P$. parasitica por meio de inoculações in vitro, medindo a porcentagem de plantas sadias. Os resultados das inoculações em laboratório concordaram com as reações de campo (Figura 1).

Este ensaio teve como objetivo avaliar, in vitro, a reação de porta-enxertos para citros a $P$. parasitica visando a seleção precoce de genótipos a gomose.

As sementes dos genótipos 'Siciliano' (Citrus limon), 'Rugoso da África' (C. jambhiri Lush.), 'Volkameriano' ( $C$. volkameriana Ten. \& Pasq.), 'Sun Chu Sha Kat' (Citrus sp.), 'Azeda' (C. aurantium L.), 'Sunki' (C. Sunki Hort ex.. Tan.), 'Cravo' [C. limonia (L.) Osbeck], 'Caipira' (C. sinensis Osbeck), Citrumelo 'Swingle' [P. trifoliata (L.) Raf. vs. C. paradisi Macf.), 
Avaliação in vitro de genótipos de citros a Phytophthora parasitica

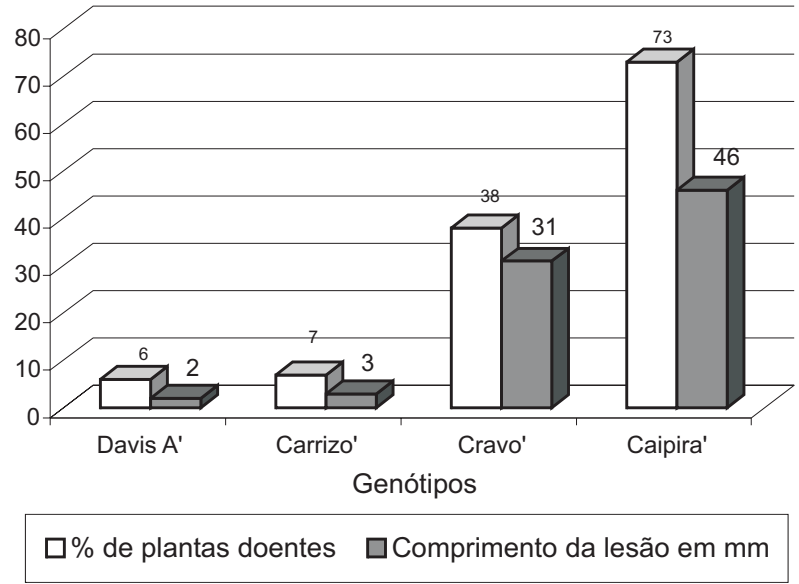

FIG 1 - Incidência de plantas doentes e comprimento de lesões causadas $P$. parasitica em quatro porta-enxertos de citros via inoculação in vitro.

tangerina 'Cleópatra' (C. reshni Hort ex.. Tan.) e citrange 'Carrizo' (C. sinensis vs. P. trifoliata) foram lavadas em água corrente e desinfestadas superficialmente em álcool $70 \%$, por 5 min, e em solução a $25 \%$ de hipoclorito de sódio. Após secagem foram colocadas assepticamente em meio de cultura específico para geminação e crescimento em condições ambientais.

As plântulas foram cultivadas em tubos de ensaio com capacidade de 20,0 $\mathrm{ml}$ contendo $3,0 \mathrm{ml}$ de meio de cultura MT (Murashigue \& Tucker, 1969), suplementado com 0,1 mg/ 1 de Benzilamilopurina (BAP) e $1 \mathrm{mg} / \mathrm{l}$ de ácido indol butírico (AIB) para uniformizar o enraizamento. As plântulas permaneceram em câmara de crescimento por um período de 40 dias. Nos dez primeiros dias foram mantidas a $27^{\circ} \mathrm{C}$ na ausência de luz, para estimular o estiolamento e, $\log$ o após, foram submetidas a fotoperíodo de $18 \mathrm{~h}$, na mesma temperatura.

O método de inoculação consiste em realizar pequenos ferimentos com o auxílio de agulha infestada com micélio do patógeno na região do colo das plântulas. O micélio do patógeno foi retirado de colônias de $P$. parasitica com sete dias de idade. A agulha foi infestada através do contato com a cultura do patógeno em placa de Petri. Em seguida, foram realizados pequenos ferimentos na região do colo das plântulas permitindo-se o contato do patógeno com o interior da plântula. O delineamento experimental foi o inteiramente casualizado. Para cada genótipo foram inoculadas 17 plantas (repetições) sendo 15 plantas úteis e duas testemunhas feridas com agulha estéril, perfazendo um total de 68 plantas inoculadas. A avaliação foi realizada aos dez dias após a inoculação do patógeno medindo-se o comprimento das lesões em $\mathrm{cm}$. Os resultados podem ser visualizados na Tabela 1.

O método permite avaliar um grande número de genótipos em pequeno espaço físico e de tempo. Entre as desvantagens do método está a exigência de laboratório e mãode-obra especializada, envolvendo custos, e o fato de que o genótipo a ser selecionado deve ser obtido de sementes, o que leva à seleção tardia de material, nem sempre desejável em programas de melhoramento de citros. O fator custo é relativo quando comparado ao custo dos tratos culturais dispensados na formação de mudas e condução das plantas no campo. As inoculações em mudas e em plantas adultas de citros, no campo, são realizadas geralmente após quatro anos. Utilizando o método de inoculação em condições axênicas, a partir das sementes das plantas, num prazo de 40 dias, conseguiu-se obter resposta de reação de resistência dos genótipos ao patógeno. A técnica pode ser de grande utilidade em trabalhos envolvendo seleção de resistência varietal de genótipos ao patógeno.

O método de inoculação in vitro distinguiu genótipos de porta-enxerto para citros quanto à resistência a P. parasitica e pode ser utilizado na seleção precoce na fase de plântulas. Os resultados da reação de resistência/suscetibilidade dos genótipos em campo citados na literatura (Feichtenberger, 2001) estão em concordância com as reações encontradas nas inoculações in vitro.

TABELA 1 - Resistência de genótipos de citros (Citrus spp.) a gomose de Phytophthora via inoculação in vitro

\begin{tabular}{ll}
\hline \hline Genótipo & \multicolumn{1}{c}{$\begin{array}{c}\text { Média das } \\
\text { Notas* }\end{array}$} \\
\hline 'Siciliano' ( Citrus limon) & $2,262 * \mathrm{~A}$ \\
'Rugoso da África' (C. jambhiri) & $2,241 \mathrm{AB}$ \\
'Volkameriano' ( C. volkameriana) & $2,068 \mathrm{ABC}$ \\
'Sun Chu Sha Kat' ( Citrus sp.) & $1,977 \mathrm{ABCD}$ \\
'Azeda' (C. aurantium) & $1,73 \mathrm{ABCDE}$ \\
'Sunki' ( C. Sunki) & $1,713 \mathrm{ABCDE}$ \\
'Cravo' (C. limonia) & $1,711 \mathrm{ABCDE}$ \\
'Caipira' ( C. sinensis) & $1,515 \mathrm{ABCDE}$ \\
Citrumelo 'Swingle' (P. trifoliata vs. C. paradisi $)$ & $1,43 \mathrm{BCDEF}$ \\
tangerina 'Cleópatra' ( C. reshni) & $1,402 \mathrm{CDEF}$ \\
citrange 'Carrizo' ( C. sinensis vs. P. trifoliata) & $1,229 \mathrm{DEF}$ \\
Poncirus trifoliata 'Rubidoux' & $1,171 \mathrm{DEF}$ \\
Poncirus trifoliata 'Davis-A' & $0,934 \mathrm{EF}$ \\
citrange 'Troyer' (C. sinensis vs. P. trifoliata ) & $0,755 \mathrm{~F}$ \\
\hline
\end{tabular}

*Médias seguidas de uma mesma letra não diferem entre si pelo teste de Tukey a $5 \%$ de probabilidade. $(\mathrm{CV}=44,58 ;$ Média = 1,537; D.M.S. $=0,832)$. Valores transformados em raiz de $\mathrm{x}+0,5$.

\section{REFERÊNCIAS BIBLIOGRÁFICAS}

BOWMAN, K.D. Screening Trifoliata hybrids citrus rootstocks for resistance to Phytophthora nicotianae by in vitro inoculation. HortScience 31:591. 1996.

BOWMAN, K.D. \& GRAHAM, J.H. In vitro evaluation of citrus rootstocks for resistance to Phytophthora nicotianae. www.nal.usda.gov/ttic/tektran/data/00007/23/0000072353 html. 1996.

CRINO, P., CRISTINZIO, G., GENTILE, A., HAEGI, A., RUGINI, 


\section{A. Siviero et al.}

E. \& SORESSI, G.P. Culture filtrates and toxins in the selection of disease resistant plants. Petria 6:197-217. 1996.

FEICHTENBERGER, E. Doenças incitadas por Phytophthora em citros. In: Luz, E.D.M.N. et al. (Ed.). Doenças causadas por Phytophthora no Brasil. São Paulo. Livraria Rural Editora, 2001. pp.283-342.

MURASHIGUE, T. \& TUCKER, W. F. Growth factor requirements of citrus tissue culture. In: Proceedings, International Citrus
Symposium, Riverside, USA, V.3, 1969, pp.1155-1166.

SIVIERO, A., SANTOS, F.A., FURTADO, E.L. \& MACHADO, M.A. Avaliação in vitro de porta-enxertos de citros a Phytophthora parasitica. Fitopatologia Brasileira 26:425.2001. (Resumo).

VARDI, A., EPSTEIN, E. \& BREIMAN, A. Is the Phytophthora citrophthora culture filtrate a reliable tool for in vitro selection of resistant Citrus variants?. Theoretical Applied Genetics, 72:569-574. 1986. 